\title{
Preferential processing of task-irrelevant beloved-related information and task performance: Two event-related potential studies
}

\author{
Sandra J.E. Langeslag ${ }^{\mathrm{a}, *}$, Jan W. van Strien ${ }^{\mathrm{b}}$

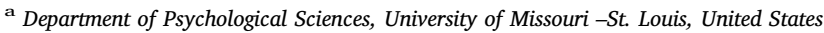 \\ b Department of Psychology, Education and Child Studies, Erasmus University Rotterdam, The Netherlands
}

\section{A R T I C L E I N F O}

\section{Keywords:}

Romantic love

Event-related potentials (ERP)

Early posterior negativity (EPN)

Late positive potential (LPP)

Attention

Short-term memory

Cognition

\begin{abstract}
A B S T R A C T
People who are in love have better attention for beloved-related information, but report having trouble focusing on other tasks, such as (home)work. So, romantic love can both improve and hurt cognition. Emotional information is preferentially processed, which improves task performance when the information is task-relevant, but hurts task performance when it is task-irrelevant. Because beloved-related information is highly emotional, the effects of romantic love on cognition may resemble these effects of emotion on cognition. We examined whether beloved-related information is preferentially processed even when it is task-irrelevant and whether this hurts task performance. In two event-related potential studies, participants who had recently fallen in love performed a visuospatial short-term memory task. Task-irrelevant beloved, friend, and stranger faces were presented during maintenance (Study 1), or encoding (Study 2). The Early Posterior Negativity (EPN) reflecting early automatic attentional capturing and the Late Positive Potential (LPP) reflecting sustained motivated attention were largest for beloved pictures. Thus, beloved pictures are preferentially processed even when they are task-irrelevant. Task performance and reaction times did not differ between beloved, friend, and stranger conditions. Nevertheless, self-reported obsessive thinking about the beloved tended to correlate negatively with task performance, and positively with reaction times, across conditions. So, although task-irrelevant belovedrelated information does not impact task performance, more obsessive thinking about the beloved might relate to poorer and slower overall task performance. More research is needed to clarify why people experience trouble focusing on beloved-unrelated tasks and how this negative effect of love on cognition could be reduced.
\end{abstract}

\section{Introduction}

There are different types of love (Berscheid, 2010; Fisher, 1998; Hatfield, 1988; Sternberg, 1986), including infatuation (or passionate love) and attachment (or companionate love). Infatuation is the overwhelming, amorous feeling for one individual that is typically most intense during the early stage of love, while attachment is the comforting feeling of emotional bonding with another individual that takes some time to develop (Fisher, 1998; Hatfield, 1988; Langeslag et al., 2013). Even though infatuation and attachment are negatively correlated, they are not mutually exclusive as people can experience both infatuation and attachment for someone at the same time (Langeslag et al., 2013). In this manuscript, the terms 'romantic love', 'love' or 'in love' are used when the specific type of love is either irrelevant or unknown. Romantic love affects cognition in various ways. For example, people who had recently fallen in love had enhanced memory for words that are related to their beloved (Langeslag et al., 2015). On the other hand, more intense infatuation has been linked to reduced cognitive control (Van Steenbergen et al., 2014). Taken together, it appears that romantic love is associated with both improved and deteriorated cognition.

It is well known that several cognitive processes, including memory and attention, are enhanced for emotionally valenced and/or arousing information compared to neutral, non-arousing information (Compton, 2003; Kensinger, 2004; Phelps, 2004). The beloved is an emotionally salient stimulus, as apparent from findings that people rate information that is related to their beloved as highly positively valenced and/or highly arousing (Guerra et al., 2011; Langeslag et al., 2015; Langeslag and Van Strien, 2016; Vico et al., 2010). So, the effects of romantic love on cognition may show overlap with the effects of emotion on cognition. Because infatuation is associated with more intense emotions than attachment (Langeslag et al., 2013), the current research focuses on the early stages of love during which infatuation is typically most intense.

Emotional information is preferentially processed regardless of whether it is relevant to the task at hand or not (Compton, 2003). Notably, people who had recently fallen in love reported to think about

\footnotetext{
* Corresponding author.

E-mail address: langeslags@umsl.edu (S.J.E. Langeslag).
} 
their beloved for 65\% (range 27-93\%) of their waking hours (Langeslag et al., 2012), which is striking. It seems unlikely that all of that thinking is actually related to a current task, such as interacting with the beloved. It may thus very well be that people prioritize processing of beloved-related information even when it is irrelevant to the task at hand, but this has not been tested yet.

Event-related potentials (ERPs) have been used extensively to study the effect of emotion on cognition (Hajcak et al., 2011; Schupp et al., 20062006a), and different ERP components provide information about the different processing stages (Linden, 2007; Luck, 2005). The early posterior negativity (EPN) is a relative negativity over the occipital scalp that occurs around $200 \mathrm{~ms}$ after stimulus onset and reflects early automatic attentional capture (Olofsson et al., 2008; Schupp, Flaisch, Schupp et al., 20062006a). The EPN occurs for emotionally arousing stimuli that have evolutionary significance, such as snakes (Van Strien et al., 2014), erotic scenes (Schupp et al., 2006; Schupp et al., 2006b, 2007), emotional scenes (Junghöfer et al., 2001), faces with emotional expressions (Calvo and Beltrán, 2013; Rellecke et al., 2012), and faces that are attractive (Werheid et al., 2007). Even though an EPN has been observed for stimuli that had to be counted compared to not counted, it has also been shown that the EPN occurred for evolutionarily-relevant stimuli regardless of the instruction to count those stimuli or not (Schupp et al., 2007). This is in line with the notion that emotional information is preferentially processed even when it is task-irrelevant (Compton, 2003). To our knowledge, it has not been tested yet whether beloved-related information elicits an EPN. Romantic love plays a major role in reproduction (Fisher, 1998), so beloved-related information has obvious evolutionary significance. Therefore, it seems likely that beloved-related information would capture early automatic attention even when it is task-irrelevant.

The late positive potential (LPP) is a posterior positivity that is typically larger for emotionally arousing than neutral information starting around $400 \mathrm{~ms}$ after stimulus onset (Hajcak et al., 2010) and is thought to reflect motivated attention (Schupp et al., 2006a). Even though the LPP is larger for stimuli that are attended, it has also been shown that the LPP is larger for emotional than neutral stimuli under passive viewing conditions (Schupp et al., 2007), which corresponds with the notion that emotional information is preferentially processed even when it is task-irrelevant (Compton, 2003). Several studies have shown that the LPP is larger for pictures of the beloved compared to pictures of friends, celebrities, or strangers, when the pictures are taskrelevant, such as when participants are counting certain pictures or keeping track of who was depicted on the last picture (Burdwood and Simons, 2016; Langeslag et al., 2008; Langeslag et al., 2008, 2007). Other studies have shown that the LPP is enhanced for beloved-related pictures and words compared to information that is related to friends, parents, babies, or strangers under passive viewing conditions as well (Guerra et al., 2011; Langeslag et al., 2015; Langeslag and Van Strien, 2016). In one of the studies, the LPP was enhanced for task-relevant beloved pictures even when participants were instructed to count the friend rather than the beloved pictures (Langeslag et al., 2008). Therefore, it seems likely that the people would also have enhanced motivated attention for beloved-related information that is completely irrelevant to the task at hand.

Two other ERP components of interest are the P1 and the N170. The $\mathrm{P} 1$ is a positive peak that is maximal around $100 \mathrm{~ms}$ after stimulus onset over the posterior scalp and is thought to reflect early visual processing. The P1 is larger for attended than unattended stimuli (Hillyard et al., 1998). The findings regarding the effect of emotion on the P1 are mixed (Hajcak et al., 2011), with some studies showing that the P1 is enhanced for emotional stimuli (e.g., Carretié et al., 2004) and others showing that it is not (e.g., Langeslag et al., 2009). The N170 is a negative peak that is maximal around $170 \mathrm{~ms}$ after stimulus onset over the posterior scalp that is thought to reflect the structural encoding of face stimuli (Bentin et al., 1996). In a previous study, the N170 for faces was larger when they were attended than when they were not attended
(Holmes et al., 2003). The findings regarding the effect of emotion on the N170 are mixed as well (Hajcak et al., 2011), with some studies showing that the $\mathrm{N} 170$ is enhanced for faces with emotional expressions (e.g., Batty and Taylor, 2003), and other studies showing that it is not (e.g., Holmes et al., 2003). To our knowledge, it has not been tested yet whether beloved-related information elicits an enhanced P1 and/or N170.

Our first research question is whether beloved-related information is preferentially processed even when it is task-irrelevant, and if so, during which processing stage(s) this preferential processing occurs (i.e., early visual processing, structural face processing, early automatic attention, and/or motivated attention). We conducted two studies in which participants who had recently fallen in love performed a neutral task (i.e., a short-term memory task for abstract shapes (Anticevic et al., 2010)) during which task-irrelevant pictures of the beloved, a friend, and a stranger were presented. It was expected that there would be an EPN for beloved compared to friend and stranger pictures, which would suggest that beloved-related information captures early automatic attention even when it is task-irrelevant. It was also expected that the LPP would be enhanced for the beloved compared to friend and stranger pictures, which would indicate that beloved-related information elicits enhanced motivated attention even when it is task-irrelevant. Because previous findings regarding the effect of emotion on the P1 and N170 have been mixed, we had no hypotheses about these ERP components. A larger P1 and N170 for beloved compared to friend and stranger pictures would suggest that early visual processing and structural face processing are enhanced for beloved-related information that is irrelevant to the task, respectively.

While prioritized processing of emotional information that is taskrelevant leads to improved task performance, prioritized processing of task-irrelevant emotional information leads to diminished task performance (Dolcos et al., 2011). For example, when participants worried about something they showed reduced task performance because worrying used up the limited processing resources available (Sari et al., 2017). Likewise, the presentation of task-irrelevant emotional pictures during a short-term memory task decreased task performance compared to when neutral pictures were presented (Anticevic et al., 2010; Dolcos and McCarthy, 2006). Notably, infatuated individuals endorse questionnaire items like "My thoughts about _ make it difficult for me to concentrate on something else" (Hatfield and Sprecher, 1986; Langeslag et al., 2013). Correspondingly, it has been shown that more thinking about an ex-partner was associated with poorer performance on a reading comprehension test (Baird et al., 2013). It thus could be that prioritized processing of information related to a current beloved distracts people who are in love from other tasks, but this has not been tested yet.

Therefore, our second research question is whether the enhanced processing of task-irrelevant beloved-related information has a negative impact on task performance. We used two different approaches to answer this research question. First, we compared task performance and reaction times between the conditions in which task-irrelevant pictures of the beloved, the friend, or a stranger were presented. It was expected that participants would perform worse and/or slower when the taskirrelevant pictures were of the beloved rather than of a friend or a stranger. We also expected that greater preferential processing as measured by the ERP components would be associated with poorer and/or slower task performance. However, because participants may still be thinking about their beloved even in the absence of a picture of their beloved, the second approach was to measure the extent of obsessive thinking about the beloved with questionnaires and to test if this self-reported obsessive thinking about the beloved was related to task performance regardless of which picture was presented as task-irrelevant information. We expected that more obsessive thinking about the beloved would be associated with poorer and/or slower overall task performance.

In Study 1, the task-irrelevant faces were presented in the 


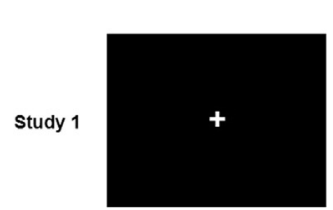

$400-600 \mathrm{~ms}$

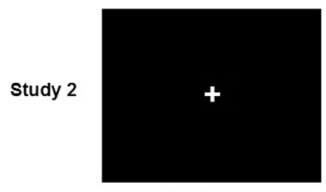

$400-600 \mathrm{~ms}$

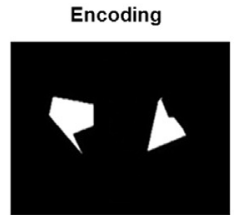

$3000 \mathrm{~ms}$

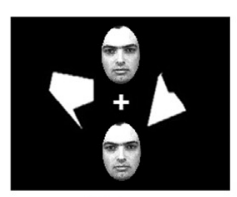

$3000 \mathrm{~ms}$

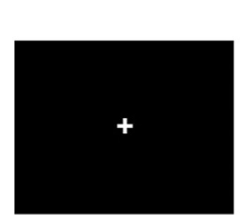

$1900-2100 \mathrm{~ms}$

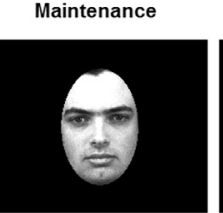

$2000 \mathrm{~ms}$

$6000 \mathrm{~ms}$

$1900-2100 \mathrm{~ms}$
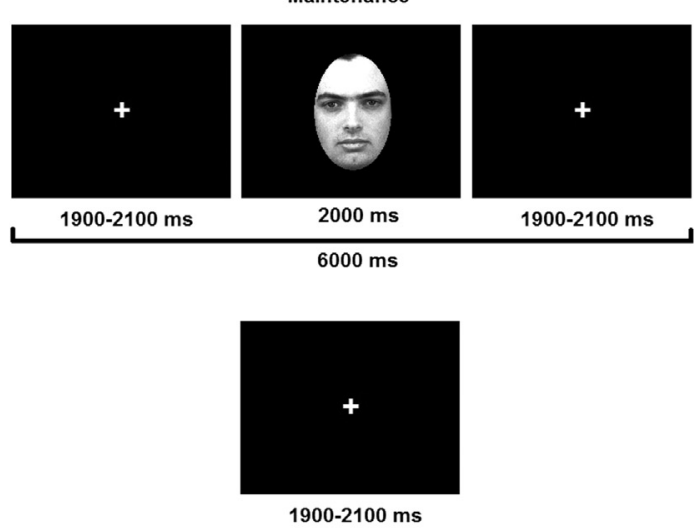

$1900-2100 \mathrm{~ms}$

Fig. 1. Task overview studies 1 and 2. Images are not to scale.
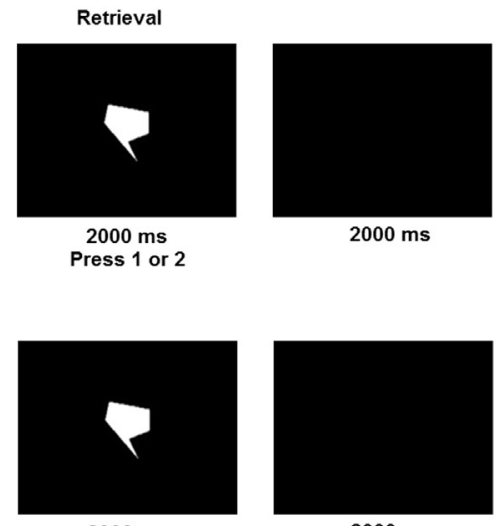

$2000 \mathrm{~ms}$ $2000 \mathrm{~ms}$
Press 1 or 2

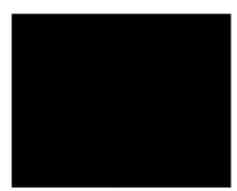

$2000 \mathrm{~ms}$ maintenance phase of the short-term memory task, in keeping with previous studies (Anticevic et al., 2010; Dolcos and McCarthy, 2006; Jackson et al., 2012). In Study 2, in contrast, the task-irrelevant faces were presented in the encoding phase alongside the to-be-remembered shapes and participants were explicitly instructed to ignore the faces. To our knowledge, no previous studies have presented emotional taskirrelevant information in the encoding phase of a short-term memory task. An advantage of this design is that the task-irrelevant faces directly compete for processing resources with the task-relevant shapes.

The importance of answering our research questions arises from the major impact that love has on people's lives, combined with its high prevalence. Specifically, love has many positive and negative effects, which includes the improvement and deterioration of cognition that is the focus of the current studies. Moreover, love has been observed in almost all cultures that have been studied (Jankowiak and Fischer, 1992) and the large majority of people becomes involved in a romantic relationship at some point (Carver et al., 2003). In other words, romantic love with all of its positive and negative effects pertains to virtually everyone.

\section{Study 1}

\subsection{Methods}

Twenty-six students of the Erasmus University Rotterdam in The Netherlands who were in love by self-report volunteered to participate. One participant was excluded because her electroencephalogram (EEG) data were not recorded and one participant was excluded because of chance performance (see below), so 24 participants (18-28 yrs, $M=$ 20.9, 13 men) were included in the analysis. Having an opposite-sex beloved was an inclusion criterion, so that all face pictures used in the task could be of an opposite-sex individual (see below). Because infatuation decreases over time and is assumed to last up to 1.5 years (Fisher et al., 2002; Langeslag et al., 2013), only participants who had been in love for less than 1 year were included. Other inclusion criteria were normal or corrected-to-normal vision, no neurological or mental disorders, and no use of medication known to affect the central nervous system. All participants were right-handed as determined by a hand preference questionnaire (Van Strien, 1992). The study was approved by the institutional review board of the Erasmus University Rotterdam and participants provided written informed consent at the start of the testing session. Participants were remunerated with course credit or $€ 15$.

\subsubsection{Stimuli}

The task-irrelevant stimuli were photographs of the faces of the participants' beloved and friends, and of a person that was unknown to them. A friend was defined as someone of the opposite sex that the participants knew and liked, but did not have any romantic feelings for. The friend stimulus was included to control for familiarity (cf. Langeslag et al., 2008, 2007), and the stranger was included as a baseline condition. The photographs of the beloved and friend were supplied by the participants and were digitally adjusted to show a grayscaled, ovally-cropped face on a black background. The stranger faces were a male and a female face with a neutral facial expression from the Karolinska KDEF database (Lundqvist et al., 1998). Five research assistants (21-39 yrs, $M=28.0,2$ men) who did not know which faces were beloveds, friends, and strangers rated the valence of the facial expressions ( $1=$ negative, $5=$ neutral, $9=$ positive $)$ using a computerized version of the Self-Assessment Manikin (Bradley and Lang, 1994). Numerically, the facial expressions of the friends were most positive $(M=6.9, S D=.6)$, the facial expressions of the beloveds were intermediately positive $(M=6.4, S D=.5)$, and the facial expressions of the strangers were neutral $(M=4.9, S D=.4)$. The male participants viewed only female faces, whereas the female participants viewed male faces (i.e., the beloved and friend were of the opposite sex, the male participants viewed an unknown female and the female participants viewed an unknown male). Keeping the gender of the face stimuli constant between the beloved, friend, and stranger pictures within participants prevented confounding of condition effects by stimulus gender. In addition, presenting only opposite-sex faces (as opposed to additionally including participants who had a same-sex beloved, and presenting same-sex beloved, friend, and stranger pictures to them) reduced between-participant variance related to differences between processing same- vs. opposite-sex faces, homo- vs. heterosexual love, and same- vs. opposite-sex friendships.

The memoranda for the short term memory task were white, abstract shapes on a black background (Anticevic et al., 2010), see Fig. 1. In the encoding phase of the task (see below), two shapes were presented, one on the left and one on the right of the screen. Each pair of two different encoding shapes was associated with four potential probe shapes: the left shape, the right shape, a shape that was somewhat similar to, yet different from the left shape, and a shape that was somewhat similar to, yet different from the right shape. Single probe shapes were presented during the retrieval phase of the task (see below).

\subsubsection{Procedure}

First, participants completed some questions about their love feelings, and their romantic relationship and friendship (Langeslag et al., 2015). Specifically, participants indicated for how long they had known their beloved, and for how long they had romantic feelings for him/her. They also indicated how well they knew their beloved ( $1=$ not at all, 9 $=$ very well) and whether they were involved in a romantic 
relationship with their beloved. If so, they indicated the duration of this relationship and the quality of it ( $1=$ very bad, $9=$ very good). Subsequently, participants indicated for how long they had known the friend whose picture they submitted, and for how long they had been friends. They also indicated how well they knew their friend and rated the quality of the friendship. Participants also completed the Infatuation and Attachment Scales (IAS) (Langeslag et al., 2013), and the Passionate Love Scale (PLS) (Hatfield, 1998) to assess the intensity of infatuation and attachment. Each of these questionnaires contains three items that assess obsessive thinking about the beloved and/or the distracting effect of love: "I stare into the distance while I think of _.." (IAS item 1), "My thoughts about _ make it difficult for me to concentrate on something else." (IAS item 7), "I have a hard time sleeping because I am thinking of _.." (IAS item 16), "Sometimes I feel I can't control my thoughts; they are obsessively on __.." (PLS item 5), “__ always seems to be on my mind." (PLS item 19), and "I sometimes find it difficult to concentrate on work because thoughts of _ occupy my mind." (PLS item 21).

Next, participants were introduced to the short-term memory task, see the top panel of Fig. 1. Each trial started with a fixation cross with jittered duration between 400-600 ms. Then, two shapes were presented for $3000 \mathrm{~ms}$ in the encoding phase. Participants were instructed to try to remember both shapes. In the maintenance phase, a fixation cross was presented for $1900-2100 \mathrm{~ms}$, followed by the picture of the beloved, friend, or stranger for $2000 \mathrm{~ms}$, followed by another fixation cross for 1900-2100 ms. The total length of the maintenance phase was always $6000 \mathrm{~ms}$. Participants were instructed that the faces were irrelevant for their task, but that they did have to look at them (i.e., they should not close their eyes or look away). Next, a single probe shape was displayed for $2000 \mathrm{~ms}$ in the retrieval phase. Participants pressed a button with their right index or middle finger to indicate whether the probe shape was the same as one of the two shapes in the encoding phase, or whether it was a different shape. Response mapping was counterbalanced between participants and both accuracy and speed were stressed. Responses with a response time longer than $2000 \mathrm{~ms}$ were discarded. Finally, a blank screen was presented for $2000 \mathrm{~ms}$ during the inter-trial interval. Participants were asked to limit movements and eyeblinks.

Participants first completed some practice trials with shapes and unknown faces that were not used in the rest of the task. Participants received feedback after each practice trial (correct, incorrect, too slow). Then, participants completed the main task consisting of five blocks of 24 trials each, resulting in 40 trials per face condition. No feedback was provided in the main blocks. Each block contained equal numbers of trials of each of the three face conditions. Each of the 40 encoding shape pairs was presented once in each face condition, but shape pairs were not repeated within a single block. Each of the 120 probe shapes was presented only once. Half of the trials contained a probe that was the same as one of the encoding shapes and the other half of the trials contained a probe that different from (but somewhat similar to) the encoding shapes, and this was balanced between the three face conditions and within each block. Also, half of the trials contained a probe that was the same as or similar to the left encoding shape, and the other half contained a probe that was the same as or similar to the right encoding shape, which was also balanced between the three face conditions and within each block. Trial order was pseudorandom with the constraint that trials of the same face condition appeared no more than three times in a row.

After completion of the short term memory task, the electrode cap was removed and participants rated the valence and arousal of each of the three faces with a computerized version of the Self-Assessment Manikin (Bradley and Lang, 1994).

\subsubsection{EEG recording and preprocessing}

The EEG was recorded using a 32-channel amplifier and data acquisition software (ActiveTwoSystem, BioSemi). The $32 \mathrm{Ag}-\mathrm{AgCl}$ active electrodes were placed upon the scalp by means of a head cap (BioSemi), according to the 10-20 International System. Vertical electro-oculogram and horizontal electro-oculogram were recorded by attaching additional electrodes (UltraFlat Active electrodes, BioSemi) above and below the left eye, and at the outer canthi of both eyes. Another two electrodes were attached to the left and right mastoids. An active electrode (common mode sense) and a passive electrode (driven right leg) were used to comprise a feedback loop for amplifier reference. All signals were digitized with a sampling rate of $512 \mathrm{~Hz}$, a $24 \mathrm{bit}$ A/D conversion and a low pass filter of $134 \mathrm{~Hz}$. The EEG data were analyzed with BrainVision Analyzer 2 (Brain Products, Gilching, Germany). Per participant, a maximum of one bad electrode was corrected using spherical spline topographic interpolation. Offline, an average reference was applied because that is the preferred reference for the N170 (Joyce and Rossion, 2005) and EPN (Hajcak et al., 2011), and can be used for the LPP (Hajcak et al., 2011). The data were filtered using a $.1-30 \mathrm{~Hz}$ band pass filter (phase shift-free Butterworth filters; $24 \mathrm{~dB}$ /octave slope). In addition, a $50 \mathrm{~Hz}$ (i.e., the frequency of the local electrical power lines) notch filter was used. Data were segmented in epochs covering the presentation of the picture in the maintenance phase from $200 \mathrm{~ms}$ pre-stimulus until $2000 \mathrm{~ms}$ post-stimulus onset. Ocular artifact correction was applied semi-automatically according to the Gratton and Coles algorithm, which corrects horizontal and vertical eye movements, as well as eye blinks (Gratton et al., 1983). The $200 \mathrm{~ms}$ pre-stimulus period was used for baseline correction. Artifact rejection was performed at individual electrodes with the criterion minimum and maximum baseline-to-peak -75 to $+75 \mu \mathrm{V}$. At the electrodes used in the analyses (see below), the minimum number of accepted trials per electrode per condition was 25 out of 40 and the average number of accepted trials per electrode per condition ranged from 39.2 to 39.8 .

\subsubsection{Statistical analyses}

Relationship and friendship characteristics were compared with paired $t$-tests. The valence and arousal ratings were analyzed with repeated measures analyses of variance (rmANOVAs) with the factor Picture (beloved, friend, stranger).

Because the P1 and N170 are peaks that can typically be identified in the waveforms of individual participants, peak detection was used to quantify these components. The P1 was detected as a local maximum between 80-140 ms (cf. Langeslag et al., 2009) at electrodes P7, P8, $\mathrm{O} 1$, and $\mathrm{O} 2$. Even though the frontocentral positivity accompanying the N170 occurred more posterior than typical, the posterior negativity occurred at the typical lateral parietal electrodes, see Fig. 2. The N170 was detected as a local minimum between 140-210 ms (cf. Langeslag et al., 2009) at electrodes P7, P8, O1, and O2. For both the P1 and N170, peak amplitudes and latencies per channel were entered into rmANOVAs with factors Picture, Hemisphere (left, right), and Electrode (parietal, occipital). Because the EPN and LPP are broader ERP components without a clear peak, area measures were used to quantify these components. Visual inspection of the data revealed that the EPN elicited by the current task was maximal between $250-400 \mathrm{~ms}$, see Fig. 2. Therefore, the mean amplitudes in the $250-400 \mathrm{~ms}$ time window at electrodes P7, P8, PO3, PO4, O1, and $\mathrm{O} 2$ were subjected to a rmANOVA with factors Picture, Hemisphere, and Electrode (parietal, parieto-occipital, occipital). The LPP was quantified by mean amplitudes in 400-1000 and 1000-2000 ms time windows at electrodes F3, Fz, F4, C3, Cz, C4, P3, Pz and P4 (cf. Langeslag et al., 2007), which were subjected to rmANOVAs with factors Picture, Caudality (frontal, central, parietal) and Laterality (left, midline, right). See Fig. 3 for an overview of the electrodes included in the analysis of each of the different ERP components. Pearson correlation coefficients were computed between the EPN for beloved compared to friend pictures (averaged across electrodes O1, O2, P7, and P8) and the LPP difference between beloved and friend pictures (average across $\mathrm{Cz}$ and $\mathrm{Pz}$ ), and valence and arousal differences between beloved and friend pictures.

The hit rates ( $H$, i.e., proportion correct 'same' responses) and false 


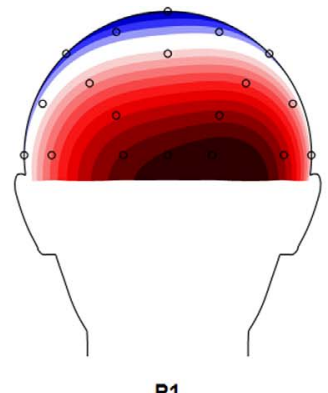

P1

$80-140 \mathrm{~ms}$

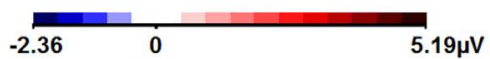

$\mathrm{Pz}$
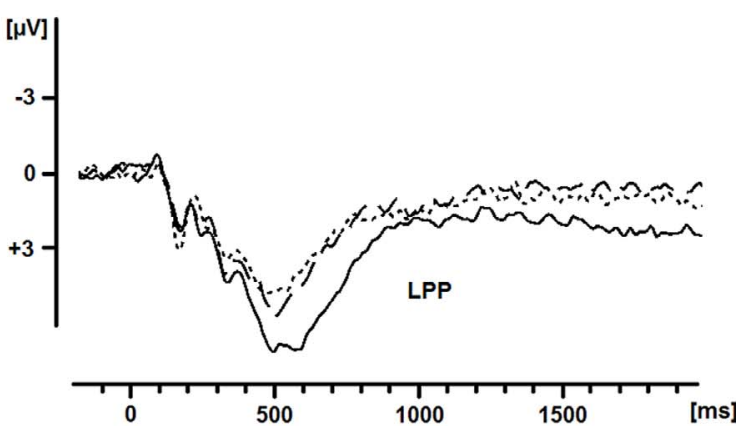

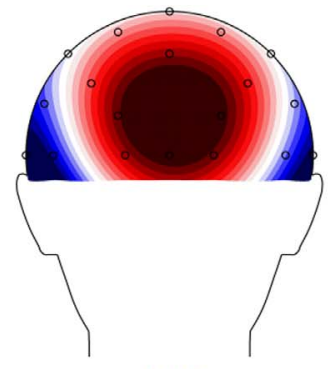

N170

$40-210 \mathrm{~ms}$

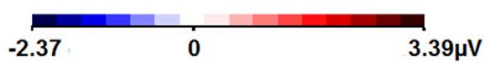

P7

P8

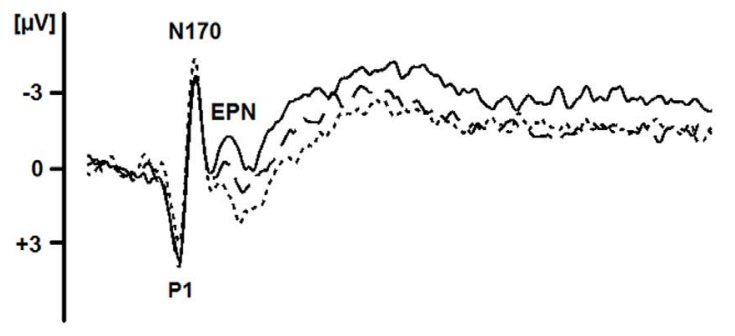

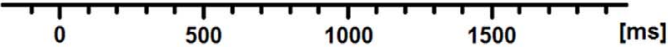

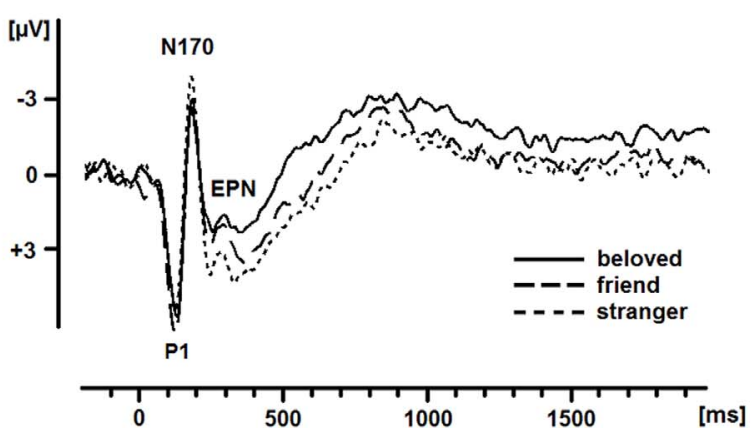

[ms]

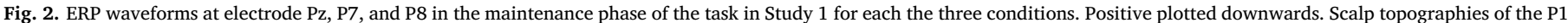
and N170 components display the average across the three conditions.

alarm rates ( $F A$, i.e., proportion incorrect 'same' responses) were computed using the correction recommended by Snodgrass and Corwin (1988). Memory performance was represented by the discrimination index $P r=H-F A$ (Snodgrass and Corwin, 1988), and by mean response times for correct responses (RTs). $P r=0$ reflects chance performance and $P r=1$ reflects perfect performance. As mentioned above, one participant who scored at chance level ( $P r$ averaged across conditions $=.01$ ) was excluded from all analyses. The discrimination index Pr, and mean RTs were analyzed with repeated measures analyses of variance (rmANOVAs) with the factor Picture (beloved, friend, stranger). Pearson correlation coefficients were computed between the discrimination index Pr and the mean RTs averaged across conditions, and the EPN for beloved compared to friend pictures (averaged across electrodes O1, O2, P7, and P8) and the LPP difference between beloved and friend pictures (averaged across $\mathrm{Cz}$ and $\mathrm{Pz}$ ).
Finally, the average score on the three items of the IAS that measured obsessive thinking about the beloved (items 1, 7, and 16) was computed, as well as the average score on the three PLS items that measured obsessive thinking about the beloved (items 5, 19, 21). Pearson correlations were computed between IAS and PLS obsessive thinking scores, and the discrimination index $\mathrm{Pr}$ and the mean RTs averaged across conditions.

Only significant effects involving the factor Picture are reported, because those are relevant for the research questions. When applicable, the degrees of freedom were corrected using the Greenhouse-Geisser correction. The $F$ values, uncorrected degrees of freedom, the $\varepsilon$ values and corrected probability values are reported. A significance level of $5 \%$ (two-sided) was selected. Follow-up paired $t$-tests were conducted according to Fisher's least significance difference (LSD) procedure, which controls type I error rate by conducting follow-up paired $t$-tests

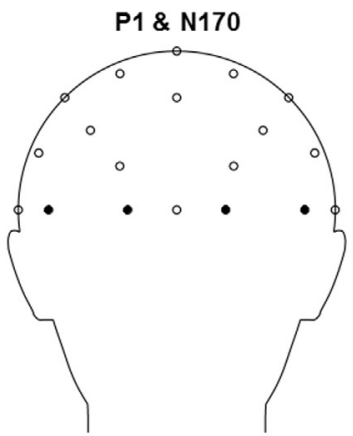

P7, 01, 02, P8

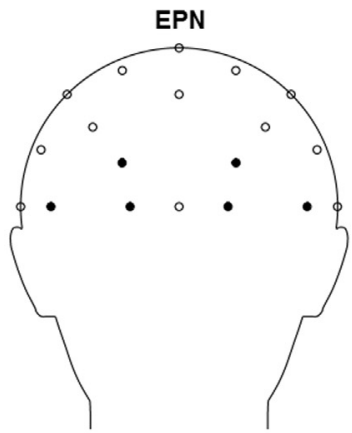

$\mathrm{PO} 3, \mathrm{PO} 4$

P7, 01, 02, P8

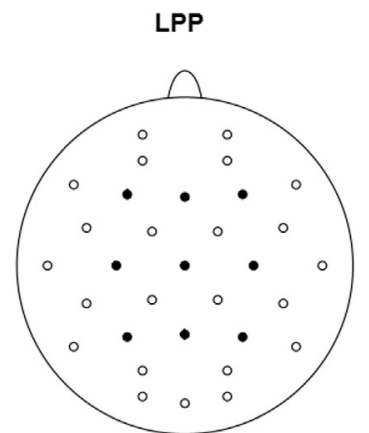

F3, Fz, F4

$\mathrm{C} 3, \mathrm{Cz}, \mathrm{C} 4$

P3, Pz, P4
Fig. 3. Electrodes included in the analysis of each of the different ERP components are in solid black. 
Table 1

Mean (ranges in parentheses) love, relationship, and friendship characteristics.

\begin{tabular}{|c|c|c|c|c|}
\hline & \multicolumn{2}{|l|}{ Study 1} & \multicolumn{2}{|l|}{ Study 2} \\
\hline & Beloved & Friend & Beloved & Friend \\
\hline Duration known [months] & $16.9(3.0-54.0)$ & $53.5(8.5-228.0)$ & $12.9(2.0-30.0)$ & $56.8(3.0-184.0)$ \\
\hline Time since start love feelings [months] & $6.4(1.0-12.0)$ & n.a. & $6.3(1.8-12.0)$ & n.a. \\
\hline Relationship/friendship duration [months] & $5.3(.3-15.0)$ & $49.0(6.0-228.0)$ & $5.8(1.0-10.0)$ & $51.2(3.0-184.0)$ \\
\hline Relationship/friendship quality [1-9] & $8.2(7.0-9.0)$ & $6.3(3.0-8.0)$ & $7.8(3.0-9.0)$ & $7.6(5.0-9.0)$ \\
\hline How well known [1-9] & $7.9(5.0-9.0)$ & $6.3(2.0-9.0)$ & $7.3(5.0-9.0)$ & $7.1(5.0-9.0)^{\mathrm{a}}$ \\
\hline IAS infatuation score [1-7] & $3.2(1.8-5.0)$ & n.a. & $3.8(2.3-6.2)$ & n.a. \\
\hline IAS attachment score [1-7] & $5.8(4.2-6.9)$ & n.a. & $5.6(1.1-6.9)$ & n.a. \\
\hline IAS obsession score [1-7] & $3.7(2.3-5.3)$ & n.a. & $4.3(1.7-6.7)$ & n.a. \\
\hline PLS score [1-9] & $7.0(5.1-8.2)$ & n.a. & $7.5(4.9-8.8)$ & n.a. \\
\hline PLS obsession score [1-9] & $5.7(3.0-7.3)$ & n.a. & $6.7(3.0-9.0)$ & n.a. \\
\hline
\end{tabular}

Note. n.a. = not applicable.

${ }^{a}=$ Data of one participant was missing.

for significant main and interaction effects only. Therefore, the followup $t$-tests were not otherwise corrected for multiple comparisons. The correlation analyses were not corrected for multiple comparisons.

\subsection{Results}

\subsubsection{Love, relationship, and friendship characteristics}

See Table 1 for love, relationship, and friendship characteristics. On average, participants had known their beloved shorter than their friend, $t(23)=-3.3, p=.003$, but reported to know their beloved better than their friend, $t(23)=4.9, p<.001$. All but one of the participants were in a relationship with their beloved. Those romantic relationships were of shorter duration, $t(22)=-3.8, p=.001$, but of better quality, $t(22)=5.7, p<.001$, than the friendships.

\subsubsection{Valence and arousal ratings}

For valence ratings, there was a main effect of Picture, $F(2,46)=$ 59.0, $\varepsilon=.67, p<.001$. Participants felt most pleasant when viewing the beloved $(M=8.3, S D=.8)$, intermediately pleasant when viewing the friend $(M=6.5, S D=1.3)$, and least pleasant when viewing the stranger $(M=4.6, S D=1.3)$, all $p$ s $<.001$. For arousal ratings, there was a main effect of Picture as well, $F(2,46)=125.3, \varepsilon=.95$, $p<.001$. Participants felt most aroused when viewing the beloved $(M$ $=7.5, S D=1.4)$, intermediately aroused when viewing the friend $(M$ $=3.0, S D=1.7)$, and least aroused when viewing the stranger $(M=$ $1.8, S D=1.3)$, all $p s<.001$.

\subsubsection{Event-related potentials}

See Fig. 2 for the ERPs in the three face conditions and the scalp topographies of the P1 and N170. For the P1 amplitude and latency, none of the effects involving the factor Picture reached significance, all $F s<2.8$, all $p s>.078$. For the N170 amplitude and latency, none of the effects involving the factor Picture reached significance either, all $F s<3.0$, all $p s>.063$.

See the left column of Fig. 4 for the scalp topographies of the EPN effects. In the $250-400 \mathrm{~ms}$ time window, there was a main effect of Picture, $F(2,46)=6.6, \varepsilon=.98, p=.003$, which was modulated by a Picture $\mathrm{x}$ Electrode interaction, $F(4,92)=6.3, \varepsilon=.62, p=.002$. The ERP at parietal electrodes was more negative for beloved compared to stranger pictures, $p<.001$. At occipital electrodes, however, the ERP was more negative for beloved compared to friend and stranger pictures, both $p s<.043$. Neither of the correlations between the EPN for beloved compared to friend and valence and arousal differences between beloved and friend pictures reached significance, $-.39<$ both $r s(22)<-.28$, both $p s>.065$.

See the left two columns of Fig. 5 for the scalp topographies of the LPP effects. In the 400-1000 ms time window, there was a main effect of Picture, $F(2,46)=16.6, \varepsilon=.69, p<.001$, which was modulated by

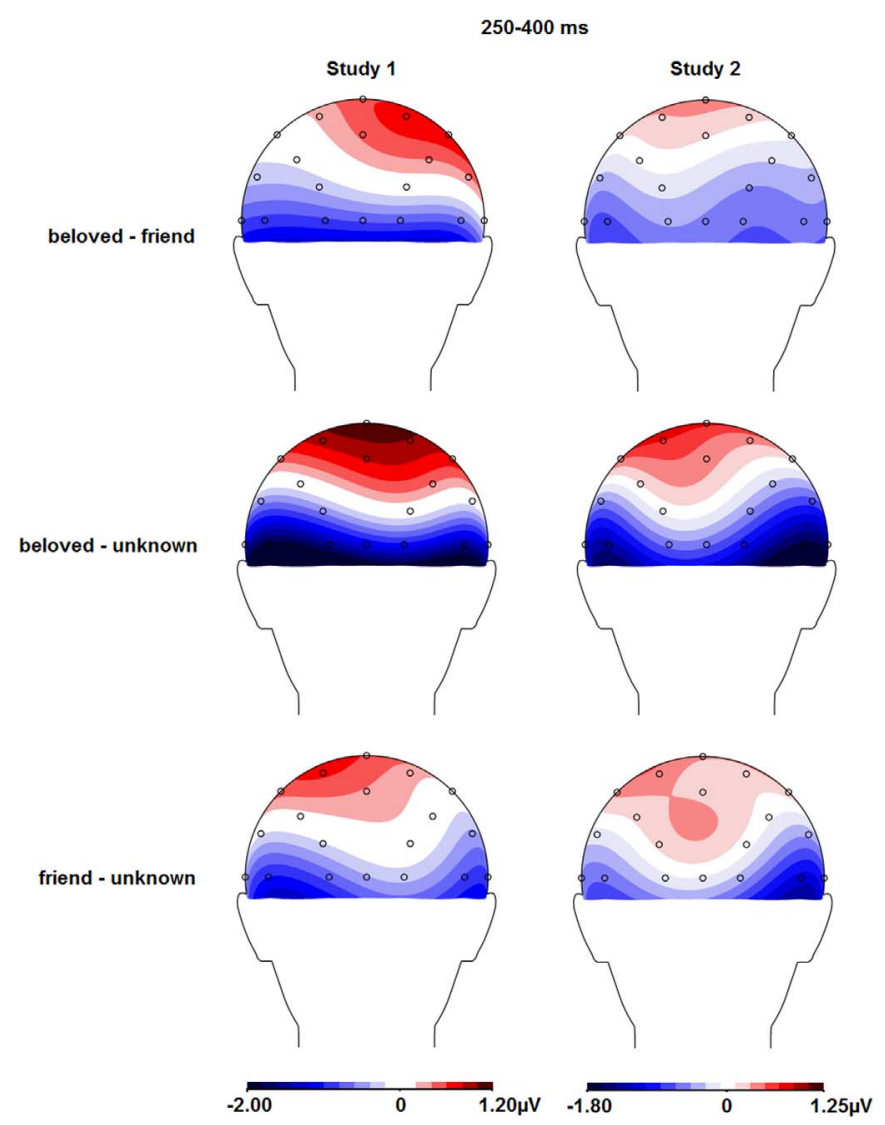

Fig. 4. EPN scalp topographies in studies 1 (left column) and 2 (right column).

a Picture $\mathrm{x}$ Laterality interaction, $F(4,92)=3.1, \varepsilon=.86, p=.027$. At left, midline, and right electrodes, the ERP was more positive for the beloved compared to the friend and the stranger pictures, all $p s<.025$. The interaction occurred because these effects were most pronounced at the midline electrodes. In the 1000-2000 ms time window, there was a main effect of Picture, $F(2,46)=3.4, \varepsilon=.92, p=.046$. The ERP was more positive for the beloved than the friend pictures, $p=.007$. Visual inspection of the data shows that the picture effects were most pronounced at centro-parietal electrodes, which corresponds with the typical posterior scalp topography of the LPP (Schupp et al., 2006a). None of the correlations between LPP differences between beloved and friend pictures in both time windows and valence and arousal differences between beloved and friend pictures were significant, $-.15<$ all $r \mathrm{~s}$ $(22)<.27$, all $p s>.19$.

To summarize, the P1 and N170 were not differentially affected by 

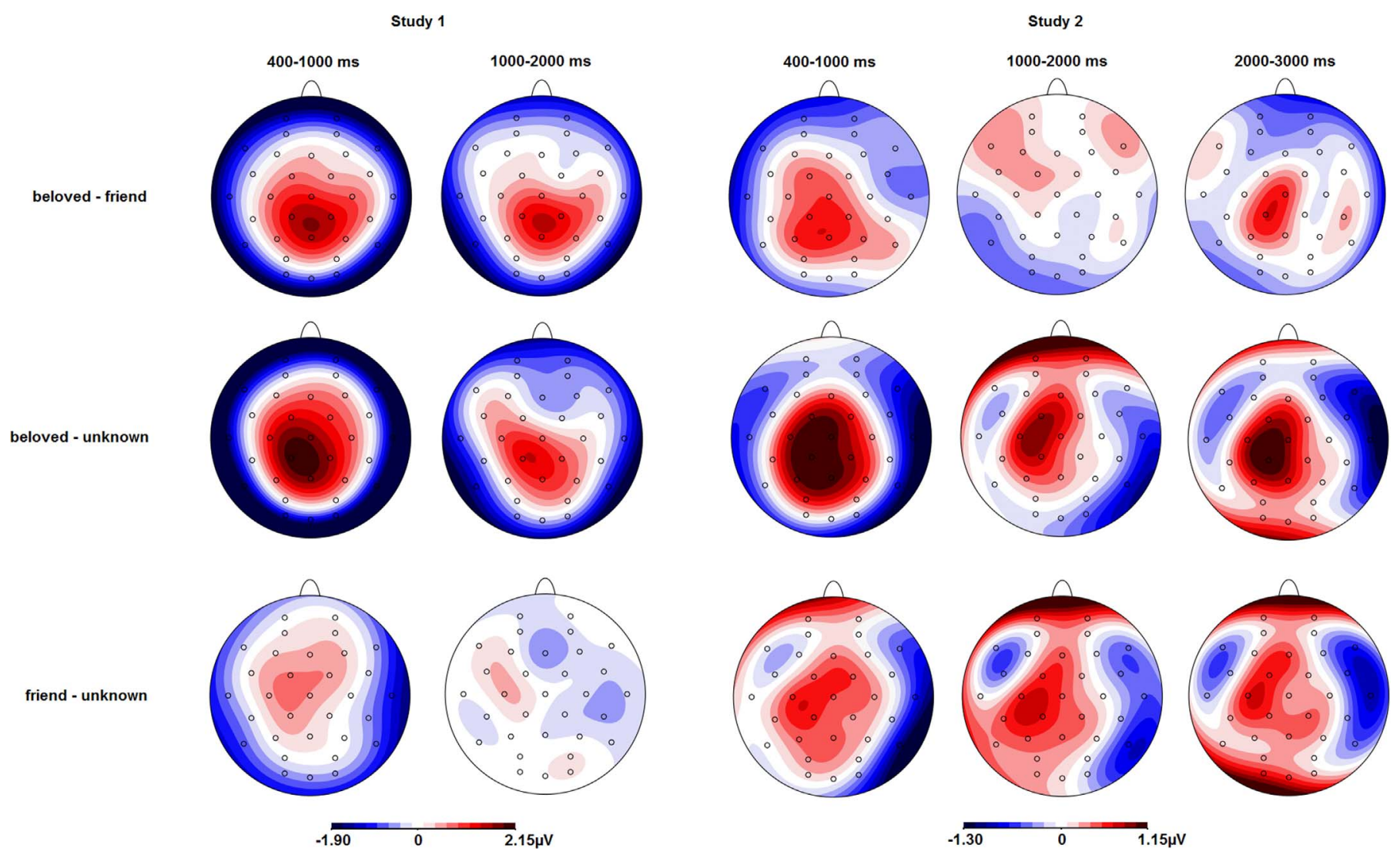

Fig. 5. LPP scalp topographies in studies 1 (left two columns) and 2 (right three columns).

the task-irrelevant pictures of the beloved, friend, and stranger. However, there was an EPN for beloved compared to friend and stranger pictures. In addition, the LPP was enhanced for beloved compared to friend pictures between 400-2000 ms after stimulus onset.

\subsubsection{Task performance}

The average discrimination index $P r$ across the three conditions was .45 (range $=.16-.77$ ). This suggests that all included participants were performing above chance level and that the task was moderately difficult. The discrimination index $\operatorname{Pr}$ did not differ between the picture conditions (beloved: $M=.48, S D=.2$, friend: $M=.44, S D=.2$, stranger: $M=.44, S D=.2), F(2,46)<1, n s$. The mean RT for correct responses averaged across the three conditions was $1103 \mathrm{~ms}$ (range $=$ 674-1365). The mean RTs for correct responses did not differ between conditions either (beloved: $M=1104 \mathrm{~ms}, S D=193$, friend: $M=$ $1103 \mathrm{~ms}, S D=150$, stranger: $M=1101 \mathrm{~ms}, S D=173), F(2,46)<1$, $n s$. The discrimination index $\mathrm{Pr}$ or mean RT differences between beloved and friend conditions did not correlate with the EPN for beloved compared to friend pictures, $-.18<$ both $r s(22)<.21$, both $p s>.33$, or with the LPP differences between beloved and friend conditions in any of the time windows, $-.02<$ all $r \mathrm{~s}(22)<.22$, all $p s>.30$. To summarize, task performance and speed were not differentially affected by (processing of) the task-irrelevant pictures.

\subsubsection{Obsessive thinking}

See Table 1 for the IAS and PLS obsession scores. The average scores on the IAS and PLS obsession items did not correlate with the discrimination index $\operatorname{Pr}$ or the mean RT averaged across conditions, $.27<$ all $r s(22)<.11$, all $p s>.20$, so self-reported obsessive thinking about the beloved was not associated with task performance or speed.

\section{Study 2}

\subsection{Methods}

The methods of Study 2 were the same as the methods of Study 1, with the exception of the following.

\subsubsection{Participants}

Twenty-five students of the University of Missouri - St. Louis in the United States volunteered to participate. One participant was excluded because his EEG data were not recorded, so 24 participants (18-34 yrs, $M=22.4,9 \mathrm{men}$ ) were included in the analysis. All participants were right-handed as determined by a hand preference questionnaire (Bryden, 1982). The study was approved by the institutional review board of the University of Missouri - St. Louis and monetary reimbursement was $\$ 25$.

\subsubsection{Stimuli}

The facial expressions of the beloveds $(M=6.5, S D=.5)$ and friends ( $M=6.5, S D=.5$ ) were equally positive, and were numerically more positive than the facial expressions of the strangers $(M=4.9, S D$ $=.4)$.

\subsubsection{Procedure}

In the short-term memory task, two task-irrelevant faces were presented in the encoding phase, alongside the task-relevant shapes, see the bottom panel of Fig. 1. The two faces were the same and were either of the beloved, the friend, or the stranger. Participants were instructed to ignore the faces as they were irrelevant to the task. In the maintenance phase, a fixation cross was presented for 1900-2100 ms.

The main task consisted of six blocks of 30 trials each, resulting in 60 trials per face condition. The 60 encoding shape pairs were not repeated until all pairs were presented, and 180 different probe shapes 
were used. The assignment of a face condition to a trial was counterbalanced between participants to rule out any effects of order or difficulty.

\subsubsection{EEG recording and preprocessing, and statistical analyses}

A $60 \mathrm{~Hz}$ notch filter was used. Because the faces were presented in the encoding phase, data were segmented in epochs covering the encoding phase from $200 \mathrm{~ms}$ pre-stimulus until $3000 \mathrm{~ms}$ post-stimulus onset. At the electrodes used in the analyses, the minimum number of accepted trials per electrode per condition was 39 out of 60 and the average number of accepted trials per electrode per condition ranged from 58.3 to 59.5 . Because the faces were presented for $3000 \mathrm{~ms}$, the LPP was also analyzed in an additional 2000-3000 ms time window.

\subsection{Results}

\subsubsection{Love, relationship, and friendship characteristics}

See Table 1 for love, relationship, and friendship characteristics. On average, participants had known their beloved shorter than their friend, $t(23)=-4.3, p<.001$, but reported to know their beloved as well as their friend, $t(22)=.4, p=.68$. All but two of the participants were in a relationship with their beloved. Those romantic relationships were of shorter duration, $t(21)=-5.0, p<.001$, but of similar quality, $t(21)$ $=.5, p=.61$, as the friendships.

\subsubsection{Valence and arousal ratings}

For valence ratings, there was a main effect of Picture, $F(2,46)=$ $72.2, \varepsilon=.94, p<.001$. Participants felt most pleasant when viewing the beloved $(M=8.5, S D=.9)$, intermediately pleasant when viewing the friend $(M=7.1, S D=1.3)$, and least pleasant when viewing the stranger $(M=4.7, S D=1.3)$, all $p s<.001$. For arousal ratings, there was a main effect of Picture as well, $F(2,46)=36.7, \varepsilon=.89, p<.001$. Participants felt most aroused when viewing the beloved $(M=6.8, S D$ $=1.9)$, intermediately aroused when viewing the friend $(M=5.0, S D$ $=2.2)$, and least aroused when viewing the stranger $(M=2.4, S D=$ $1.5)$, all $p s<.001$.

\subsubsection{Event-related potentials}

See Fig. 6 for the ERPs in the three face conditions and the scalp topographies of the P1 and N170. For the P1 amplitude, none of the effects involving the factor Picture were significant, all $F s<1$, ns. For the P1 latency, there was a main effect of Picture, $F(2,46)=4.0, \varepsilon=$ $.97, p=.026$. The $\mathrm{P} 1$ occurred earlier in response to beloved pictures $(M=113.6 \mathrm{~ms}, S D=8.1)$ than stranger pictures $(M=117.2 \mathrm{~ms}, S D=$ 9.4), $p=.006$, with the P1 latency in response to the friend picture ( $M$ $=115.3 \mathrm{~ms}, S D=10.1$ ) non-significantly different in between, both ps $>.17$.

The N170 had a more typical scalp topography than in Study 1. For the N170 amplitude, none of the effects involving the factor Picture were significant, all $F \mathrm{~s}<2.5$, all $p s>.095$. For the N170 latency, there was a significant Picture $\mathrm{x}$ Electrode interaction, $F(2,46)=3.4, \varepsilon=$ $.98, p=.042$. At occipital electrodes, the N170 occurred later in response to beloved pictures than stranger pictures, $p=.014$ (beloved: $M$ $=174.7, S D=14.3$, friend: $M=176.0, S D=14.8$, stranger: $M=$ 173.3, $S D=12.3$ ).

See the right column of Fig. 4 for the scalp topographies of the EPN effects. In the 250-400 ms time window, there was a main effect of Picture, $F(2,46)=7.4, \varepsilon=.98, p=.002$, which was modulated by a Picture $\mathrm{x}$ Electrode interaction, $F(4,92)=8.0, \varepsilon=.82, p<.001$. The ERP at occipital electrodes was more negative for beloved compared to stranger pictures, $p=.011$. At parietal electrodes, however, the ERP was most negative for beloved pictures, intermediately negative for friend pictures, and least negative for stranger pictures, all $p s<.008$. The EPN for beloved compared to friend pictures correlated negatively with the arousal difference, $r(22)=-.44, p=.032$, but not with the valence difference, $r(22)=-.19, p=.37$, between beloved and friend pictures. Because the EPN is a relative negativity, this suggests that the more arousal the beloved picture elicited compared to the friend picture, the larger the EPN for beloved compared to friend pictures.

See the right three columns of Fig. 5 for the scalp topographies of the LPP effects. In the $400-1000 \mathrm{~ms}$ time window, there was a main effect of Picture, $F(2,46)=10.8, \varepsilon=.98, p<.001$, which was modulated by a Picture $\mathrm{x}$ Laterality interaction, $F(4,92)=2.8, \varepsilon=.81$, $p=.040$. At left electrodes, the ERP was most positive in response to beloved pictures, intermediately positive in response to friend pictures, and least positive in response to stranger pictures, all $p s<.048$. At midline electrodes, the ERP was more positive in response to beloved compared to stranger pictures, $p<.001$. In the $1000-2000 \mathrm{~ms}$ time window, there was a main effect of Picture, $F(2,46)=3.9, \varepsilon=.89, p=$ .033. The ERP was more positive in response to beloved and friend compared to stranger pictures, both $p s<.037$. In the $2000-3000 \mathrm{~ms}$ time window, there was a main effect of Picture, $F(2,46)=4.9, \varepsilon=$ $.98, p=.012$. The ERP was more positive in response to beloved and friend than stranger pictures, both $p s=.012$. Visual inspection of the data shows that the picture effects were most pronounced at centroparietal electrodes, which corresponds with the typical posterior scalp topography of the LPP (Schupp et al., 2006a). The LPP differences between beloved and friend pictures in the 400-1000 ms and 1000-2000 ms time windows correlated positively with arousal differences between beloved and friend pictures, $r(22)=.47, p=.020$ and $r$ $(22)=.57, p=.004$, respectively. This suggests that the more arousal the beloved picture elicited compared to the friend picture, the larger the LPP for beloved compared to friend pictures. The LPP differences between beloved and friend pictures in the 2000-3000 ms time windows also correlated positively with arousal differences between beloved and friend pictures, but this correlation did not reach significance, $r(22)=.40, p=.053$. None of the correlations between the LPP differences between beloved and friend pictures in any of the time windows with valence differences between beloved and friend pictures were significant, $-.10<$ all $r \mathrm{~s}(22)<.21$, all $p s>.34$.

To summarize, the P1 and N170 amplitudes were not differentially affected by the task-irrelevant pictures of the beloved, friend, and stranger, but there was an EPN for beloved compared to friend and stranger pictures, similar to Study 1 . In addition, the LPP was enhanced for beloved compared to friend and stranger pictures between 400-1000 ms after stimulus onset, similar to Study 1. Between 1000-3000 ms, the LPP was enhanced for beloved and friend compared to stranger pictures, but in contrast to Study 1 no significant differences were observed between beloved and friend pictures. The more participants rated the beloved picture as more arousing than the friend picture, the larger the EPN and LPP differences between beloved and friend pictures.

\subsubsection{Task performance}

The average discrimination index $P r$ across the three conditions was .57 (range $=.35-.77$ ). This suggests that all participants were performing above chance level and that the task was moderately difficult, yet somewhat easier than the task in Study 1. The discrimination index Pr did not differ between the picture conditions (beloved: $M=.55, S D$ $=.1$, friend: $M=.58, S D=.1$, stranger: $M=.56, S D=.2), F$ $(2,46)<1, n s$. The mean RT for correct responses averaged across the three conditions was $976 \mathrm{~ms}$ (range $=670-1388$ ). The mean RTs for correct responses did not differ between conditions either (beloved: $M$ $=970 \mathrm{~ms}, S D=159$, friend: $M=971 \mathrm{~ms}, S D=181$, stranger: $M=$ $972 \mathrm{~ms}, S D=174), F(2,46)<1$, ns. The discrimination $P r$ or mean RT differences between beloved and friend conditions did not correlate with the EPN for beloved compared to friend pictures, $-.08<$ both $r \mathrm{~s}$ $(22)<-.05$, both $p s>.73$, or with the LPP differences between beloved and friend conditions in any of the three time windows, $.26<$ all $r s(22)<.25$, all $p s>.23$. So, task performance and speed were not differentially affected by (processing of) the task-irrelevant pictures, similar to Study 1. 

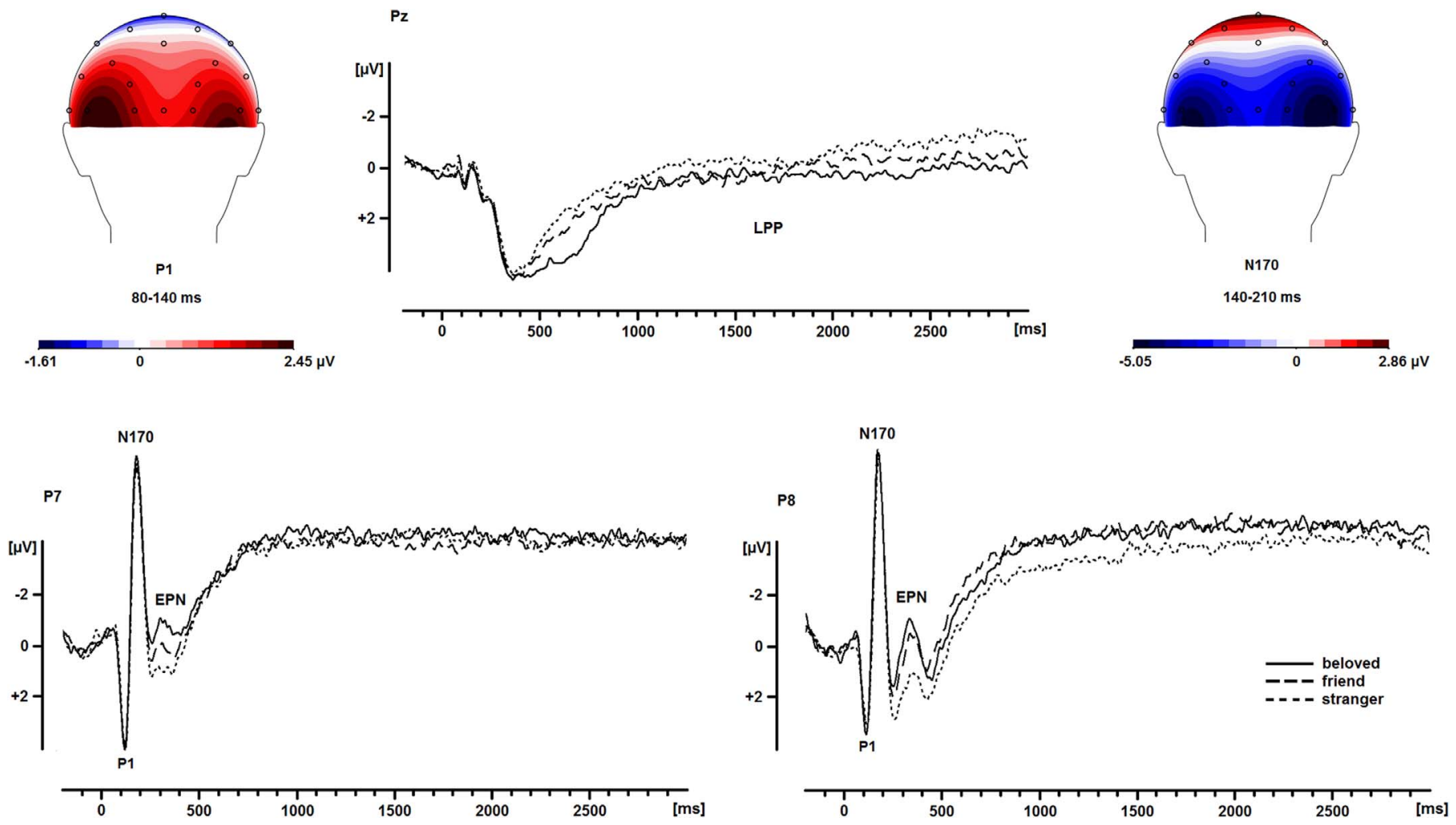

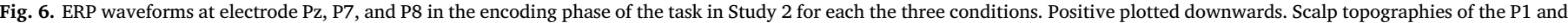
N170 components display the average across the three conditions.

\subsubsection{Obsessive thinking}

See Table 1 for the IAS and PLS obsession scores. The average score on the PLS obsession items tended to correlate negatively with the discrimination index $\operatorname{Pr}$ averaged across conditions, $r(22)=-.38, p=$ .068. This suggests that the more participants thought of their beloved, the poorer their performance on the task. The correlation between the discrimination $P r$ and the average score on the IAS obsession items was in the same direction, but not significant, $r(22)=-.24, p=.26$. The average scores on the IAS and PLS obsession items tended to correlate positively with the mean RTs averaged across conditions, both $r \mathrm{~s}(22)=$ .39 , both $p s=.059$. This suggests that the more participants thought of their beloved, the slower they responded to the probe shapes. So, in contrast to Study 1 , the associations between self-reported obsessive thinking about the beloved were in the expected direction, although they did not reach significance.

\section{Discussion}

The goal of this research was to determine whether beloved-related information is preferentially processed compared to other information even when the information is task-irrelevant. We also tested whether this preferential processing of task-irrelevant beloved-related information compared to other task-irrelevant information is associated with decreased task performance. Participants who had recently fallen in love performed a short-term memory task in which pictures of the beloved, a friend, and a stranger were presented as task-irrelevant stimuli in the maintenance (Study 1) or the encoding (Study 2) phases, while their EEG was recorded. In both studies, the picture of the beloved elicited more positive valence and higher arousal than pictures of a friend or a stranger. This is in line with previous studies (Guerra et al., 2011; Langeslag et al., 2015; Langeslag and Van Strien, 2016; Vico et al., 2010) and confirms the notion that beloved-related information is emotionally salient.

As expected, the ERP was more negative in response to pictures of the beloved than pictures of the friend or a stranger between 250-400 $\mathrm{ms}$ over the lateral posterior scalp in both studies. Because of the scalp topography (Schupp et al., 2006a), this difference is interpreted as an EPN for beloved-related information. The EPN is typically elicited using rapid serial visual presentation (RSVP) of stimuli at a rate of 3 per second (Schupp et al., 2006a). In the current studies, the beloved, friend, and stranger faces were presented at a slower rate and with longer duration. Even though the EPN in typical RSVP paradigms occurs somewhat earlier ( $\sim 200-300 \mathrm{~ms}$ ) (Schupp et al., 2006a), the EPN has previously been observed at a similar latency (i.e., 220-400 ms) as the current latency (Holmes et al., 2008). It would be informative to use a more typical RSVP paradigm to confirm the occurrence of an EPN for beloved-related information. Nevertheless, the current results suggest that beloved-related information preferentially captures early automatic attention more than friend- or stranger-related information even when the information is task-irrelevant. In Study 2, this effect even occurred when beloved-related information directly competed for processing resources with the task-relevant shapes and participants were explicitly instructed to ignore the faces. The EPN typically occurs for emotionally arousing stimuli that have evolutionary relevance (Olofsson et al., 2008; Schupp et al., 20062006a). Romantic love plays a major role in reproduction (Fisher, 1998) and the ratings confirmed that beloved-related information is highly arousing. The EPN amplitude correlated with subjective arousal, so that the more arousal the beloved picture elicited compared to the friend picture, the larger the EPN for beloved compared to friend pictures, but only in Study 2. It could be that the EPN amplitude is tightly coupled with arousal when the taskirrelevant beloved-related information is presented together with taskrelevant information, but less so when task-irrelevant beloved-related information is presented by itself. More research is needed to confirm this interpretation. Alternatively or additionally, differences between the participant samples of both studies could have caused the observed differences between the two studies in terms of the association between the EPN amplitude and subjective arousal. Most notably, the 
participants in Study 2 were more infatuated with their beloved than the participants in Study 1, see the Supplementary material. So perhaps the association between the EPN amplitude and subjective arousal is stronger as infatuation is more intense. Moreover, because Study 1 was conducted in The Netherlands and Study 2 in the US, differences between the two studies could be the result of language or cultural differences. Either way, because of its arousal and evolutionary relevance, it makes sense that beloved-related information captures early automatic attention similar to snakes, erotic scenes, emotional scenes, faces with emotional expressions, and faces that are attractive (Calvo and Beltrán, 2013; Junghöfer et al., 2001; Rellecke et al., 2012; Schupp et al., 2006; Schupp et al., 2006b, 2007; Van Strien et al., 2014; Werheid et al., 2007), and that happens even when it is task-irrelevant.

In line with the hypothesis, the ERP was more positive in response to pictures of the beloved than pictures of the friend and stranger after $400 \mathrm{~ms}$ over the central and parietal scalp in both studies. Because of the latency and scalp topography (Hajcak et al., 2010; Schupp et al., 20062006a), this finding is interpreted as an enhanced LPP for beloved compared to friend and stranger pictures. In Study 2, the enhanced LPP for beloved-related information occurred even though the task-irrelevant faces directly competed for processing resources with the taskrelevant shapes. Because beloved-related information was rated as highly arousing, this findings fits that notion that the LPP reflects arousal (Schupp et al., 2006a). The LPP amplitude correlated with subjective arousal, so that the more arousal the beloved picture elicited compared to the friend picture, the larger the LPP for beloved compared to friend pictures, but only in Study 2. Again, it could be that the LPP amplitude is tightly coupled with arousal when the task-irrelevant beloved-related information is presented together with task-relevant information, but less so when task-irrelevant beloved-related information is presented by itself (Langeslag et al., 2015). Or, because participants in Study 2 were more infatuated with their beloved than participants in Study 1, see the Supplementary material, the association between the LPP amplitude and subjective arousal might be stronger as infatuation is more intense. Language or cultural factors could have played a role as well. The enhanced LPP for beloved pictures in both studies suggests that beloved-related information receives more motivated attention than other information, even when the information is irrelevant for the task at hand. This is in line with an earlier study with an oddball task in which the LPP was larger for pictures of the beloved than a friend, regardless of whether the instruction was to count the pictures of the beloved or the friend (Langeslag et al., 2008) and extends those previous findings by showing that beloved-related information receives enhanced motivated attention even when the task does not require processing of that information at all.

There are three potential factors of confounding in this study. First, because the pictures of the beloveds and friends were supplied by the participants, it could be that the beloveds and friends differed in facial expressions. Ratings by raters who were blind to the face condition that the pictures belonged to showed that the beloved and friend faces had more positive facial expressions than the neutral stranger faces. Importantly, the friends had more positive facial expressions than the beloveds in Study 1 and the facial expressions of the beloved and friends were equally positive in Study 2 . Therefore, the more positive valence and higher arousal experienced by the participants while viewing their beloved compared to their friend were not due to differences in facial expressions. Because the EPN and LPP are typically larger for happy compared to neutral faces (Bublatzky et al., 2014; Holmes et al., 2008), the enhanced EPN and LPP for beloved compared to friend pictures were not due to differences in facial expressions either. Second, it could be that the preferential processing of belovedrelated information is due to it being familiar. Participants in both studies reported to know their beloved shorter than their friend, and the romantic relationships were of shorter duration than the friendships. In addition, participants in Study 2 reported that they knew their beloved and friend equally well and that the romantic relationships and the friendships were of similar quality. Therefore, the differences between the beloved and friend conditions in valence, arousal, EPN amplitude, and LPP amplitude are not due to having known the beloved longer than the friend or to knowing the beloved better than the friend. Still, participants may have interacted with their beloved more often lately than with their friend and/or participants may have last seen their beloved more recently than their friend. However, even though participants had never seen the stranger before the start of the testing session, no significant differences between the friend and the stranger conditions were observed in the EPN and LPP amplitudes in Study 1. This suggests that the EPN and LPP amplitudes were not modulated by frequency of recent interactions or time since last interaction. In short, it is unlikely that the enhanced EPN and LPP amplitude in response to beloved compared to friend pictures are due to differences in familiarity. Third, eye fixations could have confounded the differences between beloved and friends. In Study 2, the faces were presented alongside the to-be-remembered shapes and presentation times were long enough to allow fixations on both the faces and the shapes. Unfortunately, we did not track eye movements to measure fixation location and duration. In Study 1, however, the faces were presented by themselves in the center of the screen, which presumably resulted in fixations on the presented face only. Because the differences in EPN and LPP amplitudes between the beloved and friend were similar in both studies, it is unlikely that the EPN and LPP differences between the beloved and friend are confounded by differences in fixation location and/or duration. It would be interesting though to test when enhanced attention to beloved-related task-irrelevant information compared to other task-irrelevant information is associated with increased fixation duration.

The P1 amplitude was not differentially affected by the task-irrelevant pictures of the beloved, friend, and stranger. The N170 scalp topography was somewhat atypical in Study 1, which could have been caused by the fact that participants were maintaining the shapes while they viewed the faces. Even though the faces in Study 2 were presented alongside the to-be-remembered shapes, the N170 scalp topography was more typical in Study 2. The N170 amplitude was not differentially affected by the task-irrelevant pictures of the beloved, friend, and stranger in either of the studies. In Study 2, some effects were observed in the latencies of the P1 and N170. However, significant differences were observed between the beloved and stranger conditions only, which could just reflect the effect of positive facial expression or familiarity rather than romantic love. Moreover, the effects were in the order of a 1-2 ms, while the resolution of our EEG registration was only $1.95 \mathrm{~ms}$. We are therefore reluctant to interpret these observed effects in P1 and N170 latencies and conclude that beloved-related information was not prioritized in early visual processing or structural face processing compared to friend- or stranger-related information when it was task-irrelevant.

When task-irrelevant pictures of the beloved were presented, the participants in both studies performed the short-term memory task as well and as fast as when task-irrelevant pictures of the friend and stranger were presented. In addition, the EPN and LPP amplitudes were not associated with task performance or response speed. The behavioral results are at odds with previous studies that have shown that presenting task-irrelevant emotional compared to neutral information during the maintenance phase of a short-term memory task reduces performance (Anticevic et al., 2010; Dolcos and McCarthy, 2006). Perceptual Load Theory states that when perceptual load is high, no processing resources are left to process task-irrelevant information (Lavie, 1995). It could thus be that the current short-term memory task for shapes was so difficult that the task-irrelevant information was not processed and did thus not have a distracting effect. However, the EPN and enhanced LPP amplitude for beloved-related information show that the task-irrelevant faces were actually processed, so the absence of a distracting effect of beloved-related information does not seem to be due to the task being too difficult. The previous studies that showed 
that task-irrelevant emotional information reduces task performance used negative emotional information (Anticevic et al., 2010; Dolcos and McCarthy, 2006), whereas the task-irrelevant beloved-related information in the current study were rated as pleasant. In another previous study (Jackson et al., 2012), positive words that were presented during the maintenance phase improved short-term memory for angry faces. It may thus be that distraction is due to negative valence rather than arousal, at least in short-term memory tasks. Either way, the current findings suggest that preferential processing of task-irrelevant beloved-related information compared to other task-irrelevant information did not distract people from an unrelated short-term memory task, regardless of whether the task-irrelevant information was presented during maintenance or encoding.

In Study 1, the enhanced LPP for beloved compared to friend pictures occurred from at least $400 \mathrm{~ms}$ after stimulus onset until stimulus offset (i.e., $2000 \mathrm{~ms}$ ). In Study 2, the enhanced LPP for beloved compared to friend pictures was more confined in time, occurring only between 400-1000 ms after stimulus onset. It appeared that when the task irrelevant faces were presented together with the task-relevant shapes, participants initially paid attention to the beloved faces. Between 1000-3000 ms after stimulus onset, in contrast, participants paid similar amounts of motivated attention to the beloved and friend faces, perhaps because they were now focusing more on the task-relevant shapes. It could be that the relatively long duration of the encoding phase (i.e., $3 \mathrm{~s}$ ) gave participants the opportunity to first pay attention to the faces before shifting their attention to the shapes. This could explain why the different faces did not cause differences in task performance or why the LPP amplitude enhancement was not associated with task performance. It would be interesting to do a follow-up study with a shorter encoding phase, to test if beloved-related information would distract from a task under conditions of limited encoding time. It would also be interesting to test whether beloved-related information is distracting during other types of tasks.

One could argue that people are still in love even when they look at a picture of their friend or of a stranger. That is, while emotions are elicited by some external stimulus, love is considered to be a motivation that is more internally elicited (Langeslag, 2006). It could thus be that the effect of love on task performance occurred regardless of whether a picture of the beloved, friend, or stranger was presented. Therefore, we also tested whether obsessive thinking about the beloved in general, as measured by questionnaires administered before completing the shortterm memory task, was associated with decreased task performance. Obsessive thinking about the beloved tended to be associated with poorer and slower task performance. These correlations are in line with the hypothesis and most of them would have reached significance if we would have used one-sided testing. People who are in love report to have trouble focusing on tasks that are unrelated to the beloved, such as school or work (Hatfield and Sprecher, 1986; Langeslag et al., 2013). Correspondingly, it has been shown that more thinking about an expartner was associated with poorer performance on a reading comprehension test (Baird et al., 2013). The current correlations between obsessive thinking about the beloved and task performance should be interpreted with caution though, because of their borderline significance and because they were only observed in Study 2. Interestingly, the participants in Study 2 scored higher on the IAS obsession items than the participants in Study 1, see the Supplementary material. So perhaps the absence of an association between obsessive thinking about the beloved and overall task performance in Study 1 was due to restriction of range. As mentioned before, language or cultural factors could have played a role as well. Future studies will have to confirm whether obsessive thinking about the beloved causes people to be distracted from other things they should be doing.

To conclude, romantic love affects cognition in various ways and these effects may, at least to some extent, be the result of the arousal that beloved-related information elicits. In these two studies, we show that beloved-related information that is task-irrelevant elicits an EPN and an enhanced LPP, but not an enhanced P1 or N170, compared to other task-irrelevant information. Thus, beloved-related information is preferentially processed even when it is task-irrelevant, not because it is prioritized in early visual processing or structural face processing, but because it captures early automatic attention and receives more motivated attention than other task-irrelevant information. In contrast, there was no support for the hypothesis that this preferential processing of task-irrelevant beloved-related information negatively impacts task performance, apart from the suggestion that more obsessive thinking about the beloved might relate to poorer and slower overall task performance. More research is needed to clarify why people who are in love experience trouble focusing on beloved-unrelated tasks and how this negative effect of love on cognition could be reduced. Notably, it has been shown that cognitive reappraisal can be used to down-regulate love feelings (Langeslag and Van Strien, 2016), so future research could also test whether love down-regulation could be used to decrease any negative effects of love on cognition.

\section{Acknowledgements}

We are very grateful to Alan Anticevic for providing the shape stimuli. We thank Nikita Kalkman, Sandrine van Dommelen, and Katrina Lynn for help with the data collection.

\section{Appendix A. Supplementary material}

Supplementary data associated with this article can be found in the online version at http://dx.doi.org/10.1016/j.neuropsychologia.2017. 09.015 .

\section{References}

Anticevic, A., Repovs, G., Barch, D.M., 2010. Resisting emotional interference: brain regions facilitating working memory performance during negative distraction. Cogn. Affect. Behav. Neurosci. 10, 159-173.

Baird, B., Smallwood, J., Fishman, D.J.F., Mrazek, M.D., Schooler, J.W., 2013. Unnoticed intrusions: dissociations of meta-consciousness in thought suppression. Conscious. Cogn. 22, 1003-1012.

Batty, M., Taylor, M.J., 2003. Early processing of the six basic facial emotional expressions. Cogn. Brain Res. 17, 613-620.

Bentin, S., Allison, T., Puce, A., Perze, E., McCarthy, G., 1996. Electrophysiological studies of face perception in humans. J. Cogn. Neurosci. 8, 551-565.

Berscheid, E., 2010. Love in the fourth dimension. Annu. Rev. Psychol. 61, 1-25.

Bradley, M.M., Lang, P.J., 1994. Measuring emotion: the self-assessment manikin and the semantic differential. J. Behav. Ther. Exp. Psychiatry 25, 49-59.

Bryden, M.P., 1982. Laterality: Functional Asymmetry in the Normal Brain. Academic Press, New York.

Bublatzky, F., Gerdes, A.B.M., White, A.J., Riemer, M., Alpers, G.W., 2014. Social and emotional relevance in face processing: happy faces of future interaction partners enhance the late positive potential. Front. Hum. Neurosci. 8, 493.

Burdwood, E.N., Simons, R.F., 2016. Pay attention to me! Late ERPs reveal gender differences in attention allocated to romantic partners. Psychophysiology 53, 436-443.

Calvo, M.G., Beltrán, D., 2013. Recognition advantage of happy faces: tracing the neurocognitive process. Neuropsychologia 51, 2051-2061.

Carretié, L., Hinojosa, J.A., Mart ín-Loeches, M., Mercado, F., Tapia, M., 2004. Automatic attention to emotional stimuli: neural correlates. Hum. Brain Mapp. 22, 290-299.

Carver, K., Joyner, K., Udry, J.R., 2003. National estimates of adolescent romantic relationships. In: Florsheim, P. (Ed.), Adolescent Romantic Relations and Sexual Behavior: Theory, Research, and Practical Implications. Lawrence Erlbaum Associates Publishers, Mahwah, NJ, pp. 23-56.

Compton, R.J., 2003. The interface between emotion and attention: a review of evidence from psychology and neuroscience. Behav. Cogn. Neurosci. Rev. 2, 115-129.

Dolcos, F., McCarthy, G., 2006. Brain systems mediating cognitive interference by emotional distraction. J. Neurosci. 26, 2072-2079.

Dolcos, F., Iordan, A.D., Dolcos, S., 2011. Neural correlates of emotion-cognition interactions: a review of evidence from brain imaging investigations. J. Cogn. Psychol. 23, 669-694.

Fisher, H.E., 1998. Lust, attraction, and attachment in mammalian reproduction. Hum. Nat. 9, 23-52.

Fisher, H.E., Aron, A., Mashek, D., Li, H., Brown, L.L., 2002. Defining the brain systems of lust, romantic attraction, and attachment. Arch. Sex. Behav. 31, 413-419.

Gratton, G., Coles, M.G., Donchin, E., 1983. A new method for off-line removal of ocular artifact. Electroencephalogr. Clin. Neurophysiol. 55, 468-484.

Guerra, P., Rafaela, R.C., Vico, C., Volchan, E., Anllo-Vento, L., Vila, J., 2011. Filial versus romantic love: contributions from peripheral and central electrophysiology. Biol. Psychol. 88, 196-203. 
Hajcak, G., MacNamara, A., Olvet, D.M., 2010. Event-related potentials, emotion, and emotion regulation: an integrative review. Dev. Neuropsychol. 35, 129-155.

Hajcak, G., Weinberg, A., MacNamara, A., Foti, D., 2011. ERPs and the study of emotion. In: Luck, S.J., Kappenman, E.S. (Eds.), The Oxford Handbook of Event-related Potential Components. Oxford University Press, Oxford, pp. 441-472.

Hatfield, E., 1988. Passionate and companionate love. In: Sternberg, R.J., Barnes, M.L. (Eds.), The Psychology of Love. Yale University Press, New Haven, CT, pp. 191-217.

Hatfield, E., 1998. The passionate love scale. In: Davis, C.M., Yarber, W.L., Bauserman, R., Schreer, G., Davis, S.L. (Eds.), Handbook of Sexuality-Related Measures. Thousand Oaks Sage Publications, pp. 449-451.

Hatfield, E., Sprecher, S., 1986. Measuring passionate love in intimate relationships. J. Adolesc. 9, 383-410.

Hillyard, S.A., Vogel, E.K., Luck, S.J., 1998. Sensory gain control (amplification) as a s mechanism of selective attention: electrophysiological and neuroimaging evidence. Philos. Trans. R. Soc. B: Biol. Sci. 353, 1257-1270.

Holmes, A., Vuilleumier, P., Eimer, M., 2003. The processing of emotional facial expression is gated by spatial attention: evidence from event-related brain potentials. Cogn. Brain Res. 16, 174-184.

Holmes, A., Nielsen, M.K., Green, S., 2008. Effects of anxiety on the processing of fearful and happy faces: an event-related potential study. Biol. Psychol. 77, 159-173.

Jackson, M.C., Linden, D.E.J., Raymond, J.E., 2012. "Distracters" do not always distract: visual working memory for angry faces is enhanced by incidental emotional words. Front. Psychol. 3, 437.

Jankowiak, W.R., Fischer, E.F., 1992. A cross-cultural perspective on romantic love. Ethnology 31, 149-155.

Joyce, C., Rossion, B., 2005. The face-sensitive N170 and VPP components manifest the same brain processes: the effect of reference electrode site. Clin. Neurophysiol. 116, 2613-2631.

Junghöfer, M., Bradley, M.M., Elbert, T.R., Lang, P.J., 2001. Fleeting images: a new look at early emotion discrimination. Psychophysiology 38, 175-178.

Kensinger, E.A., 2004. Remembering emotional experiences: the contributions of valence and arousal. Rev. Neurosci. 15, 241-253.

Langeslag, S.J.E., 2006. Liefde is een motivatie, niet een emotie: een neurobiologische benadering [love is a motivation, not an emotion: a neurobiological approach]. De. Psycholoog 41, 260-265.

Langeslag, S.J.E., Van Strien, J.W., 2016. Regulation of romantic love feelings: preconceptions, strategies and feasibility. PLoS One 11, e0161087.

Langeslag, S.J.E., Jansma, B.M., Franken, I.H., Van Strien, J.W., 2007. Event-related potential responses to love-related facial stimuli. Biol. Psychol. 76, 109-115.

Langeslag, S.J.E., Franken, I.H., Van Strien, J.W., 2008. Dissociating love-related attention from task-related attention: an event-related potential oddball study. Neurosci. Lett. 431, 236-240.

Langeslag, S.J.E., Morgan, H.M., Jackson, M.C., Linden, D.E., Van Strien, J.W., 2009. Electrophysiological correlates of improved short-term memory for emotional faces. Neuropsychologia 47, 887-896.

Langeslag, S.J.E., Van der Veen, F.M., Fekkes, D., 2012. Blood levels of serotonin are differentially affected by romantic love in men and women. J. Psychophysiol. 26,
92-98.

Langeslag, S.J.E., Muris, P., Franken, I.H., 2013. Measuring romantic love: psychometric properties of the infatuation and attachment scales. J. Sex Res. 50, 739-747.

Langeslag, S.J.E., Olivier, J.R., Köhlen, M.E., Nijs, I.M., Van Strien, J.W., 2015. Increased attention and memory for beloved-related information during infatuation: behavioral and electrophysiological data. Soc. Cogn. Affect. Neurosci. 10, 136-144.

Lavie, N., 1995. Perceptual load as a necessary condition for selective attention. J. Exp. Psychol.: Hum. Percept. Perform. 21, 451-468.

Linden, D.E.J., 2007. What, when, where in the brain? Exploring mental chronometry with brain imaging and electrophysiology. Rev. Neurosci. 18, 159-171.

Luck, S.J., 2005. An Introduction to the Event-related Potential Technique. The MIT Press, Cambridge.

Lundqvist, D., Flykt, A., Öhman, A., 1998. The Karolinska Directed Emotional Faces KDEF, CD ROM from Department of Clinical Neuroscience, Psychology section, Karolinska Institutet.

Olofsson, J.K., Nordin, S., Sequeira, H., Polich, J., 2008. Affective picture processing: an integrative review of ERP findings. Biol. Psychol. 77, 247-265.

Phelps, E.A., 2004. Human emotion and memory: interactions of the amygdala and hippocampal complex. Curr. Opin. Neurobiol. 14, 198-202.

Rellecke, J., Sommer, W., Schacht, A., 2012. Does processing of emotional facial expressions depend on intention? Time-resolved evidence from event-related brain potentials. Biol. Psychol. 90, 23-32.

Sari, B.A., Koster, E.H.W., Derakshan, N., 2017. The effects of active worrying on working memory capacity. Cogn. Emot. 31, 995-1003.

Schupp, H.T., Flaisch, T., Stockburger, J., Junghöfer, M., 2006a. Emotion and attention: event-related brain potential studies. Prog. Brain Res. 156, 31-51.

Schupp, H.T., Stockburger, J., Codispoti, M., Junghöfer, M., Weike, A.I., Hamm, A.O., 2006b. Stimulus novelty and emotion perception: the near absence of habituation in the visual cortex. Neuroreport 17, 365-369.

Schupp, H.T., Stockburger, J., Codispoti, M., Junghöfer, M., Weike, A.I., Hamm, A.O., 2007. Selective visual attention to emotion. J. Neurosci. 27, 1082-1089.

Snodgrass, J.G., Corwin, J., 1988. Pragmatics of measuring recognition memory: applications to dementia and amnesia. J. Exp. Psychol.: General 117, 34-50.

Sternberg, R.J., 1986. A triangular theory of love. Psychol. Rev. 93, 119-135.

Van Steenbergen, H., Langeslag, S.J.E., Band, G.P.H., Hommel, B., 2014. Reduced cognitive control in passionate lovers. Motiv. Emot. 38, 444-450.

Van Strien, J.W., 1992. Classificatie van links- en rechtshandige proefpersonen [classification of left- and right-handed participants]. Ned. Tijdschr. voor Psychol. 66, 205-214.

Van Strien, J.W., Franken, I.H.A., Huijding, J., 2014. Testing the snake-detection hypothesis: larger early posterior negativity in humans to pictures of snakes than to pictures of other reptiles, spiders and slugs. Front. Hum. Neurosci. 8, 691.

Vico, C., Guerra, P., Robles, H., Vila, J., Anllo-Vento, L., 2010. Affective processing of loved faces: contributions from peripheral and central electrophysiology. Neuropsychologia 48, 2894-2902.

Werheid, K., Schacht, A., Sommer, W., 2007. Facial attractiveness modulates early and late event-related brain potentials. Biol. Psychol. 76, 100-108. 